\title{
Direct downstream targets of proneural activators in the imaginal disc include genes involved in lateral inhibitory signaling
}

\author{
Andrew Singson, Michael W. Leviten, ${ }^{1}$ Anne G. Bang, ${ }^{2}$ Xuequn Helen Hua, and James W. Posakony \\ Department of Biology and Center for Molecular Genetics, University of California San Diego, \\ La Jolla, California 92093-0322 USA
}

\begin{abstract}
In Drosophila imaginal dises, the spatially restricted activities of the achaete (ac) and scute (sc) proteins, which are transcriptional activators of the basic-helix-loop-helix class, define proneural clusters (PNCs) of potential sensory organ precursor (SOP) cells. Here, we report the identification of several genes that are direct downstream targets of ac-sc activation, as judged by the following criteria. The genes are expressed in the PNCs of the wing imaginal disc in an ac-sc-dependent manner; the proximal promoter regions of all of these genes contain one or two high-affinity ac-sc binding sites, which define the novel consensus GCAGGTG(T/G)NNNYY; where tested, these binding sites are required in vivo for PNC expression of promoter-reporter fusion genes. Interestingly, these ac-sc target genes, including Bearded, Enhancer of split $\mathrm{m7}$, Enhancer of split $\mathrm{m8}$, and scabrous, are all known or believed to function in the selection of a single SOP from each PNC, a process mediated by inhibitory cell-cell interactions. Thus, one of the earliest steps in adult peripheral neurogenesis is the direct activation by proneural proteins of genes involved in restricting the expression of the SOP cell fate.
\end{abstract}

[Key Words: Drosophila; neurogenesis; sensory organ development; helix-loop-helix proteins; neurogenic genes; lateral inhibition; proneural genes]

Received May 24, 1994; revised version accepted July 20, 1994

The body surface of the adult fly is covered with a complex array of multicellular sensory organs arranged in a largely invariant spatial pattern. In most cases, the cells comprising each of these organs are the progeny of a single sensory organ precursor (SOP) cell (Hartenstein and Posakony 1989|. SOPs are determined during the late larval and early pupal stages within undifferentiated epithelial sheets, the imaginal discs and histoblast nests, that ultimately give rise to the cuticular structures of the adult. The process of establishing the pattern of cells committed to the SOP fate, and thus the pattern of sensory organs, consists of at least two major steps. First, the competence to acquire the SOP cell fate is conferred on small groups of cells by the spatially restricted expression and activity of certain proneural genes, which encode transcriptional activators of the basic-helixloop-helix (bHLH) class. Then, within each of these proneural clusters, all but one of the competent cells are inhibited from expressing the SOP fate by local cell-cell interactions that depend on the activity of a second set of

Present addresses: ${ }^{1}$ Department of Molecular and Cell Biology, University of California, Berkeley, California 94720 USA; ${ }^{2}$ Molecular Neurobiology Laboratory, Salk Institute for Biological Studies, La Jolla, California 92037 USA. genes, the neurogenic genes. Following its stable determination, the SOP cell executes an invariant lineage that generates the component cells of the sensory organ (Hartenstein and Posakony 1989), a process that also requires neurogenic gene function (Posakony 1994).

The proneural genes include achaete (ac), scute (sc), and daughterless $(d a)$, which are required for the development of the external sensory organs of the adult. The spatial pattern of $a c$ and $s c$ expression is largely responsible for defining the pattern of proneural clusters for these organs /Cubas et al. 1991; Skeath and Carroll 1991), whereas $d a$ is expressed ubiquitously (Cronmiller and Cummings 1993). In a similar way, the expression of atonal (ato), a recently identified proneural gene that controls the development of chordotonal organs and photoreceptors, defines a distinct pattern of potential chordotonal SOPs and R8 photoreceptor precursors (Jarman et al. 1993, 1994).

In vitro, the ac, sc, and ato bHLH proteins each form hetero-oligomeric complexes with da that are active in sequence-specific DNA binding, and the da protein alone also exhibits DNA-binding activity (Cabrera and Alonso 1991; Van Doren et al. 1991; Jarman et al. 1993). Like other bHLH activators, these proneural proteins recognize specific sites that include a common core sequence 
(CANNTG) called the E box. More specifically, a subset of E-box sequences conforming to the consensus $\mathrm{CAG} / \mathrm{G} / \mathrm{C}) \mathrm{TG}$ have been shown to represent high-affinity in vitro binding sites for $\mathrm{da} / \mathrm{da}, \mathrm{da} / \mathrm{ac}$, and $\mathrm{da} / \mathrm{sc}$ protein complexes (Cabrera and Alonso 1991; Van Doren et al. 1991). Such sites mediate transcriptional activation by the proneural proteins in yeast and in Drosophila tissue culture cells, as well as in vivo (Cabrera and Alonso 1991; Van Doren et al. 1992; Martinez et al. 1993).

The pattern and level of $a c$ and $s c$ expression within the proneural cluster depends in part on the auto- and cross-regulatory activities of their gene products (Martinez and Modolell 1991; Van Doren et al. 1992; Martinez et al. 1993). Specifically, ac is subject to direct transcriptional activation by protein complexes that include the ac and sc proteins, and three E-box binding sites found in the proximal promoter region of the gene are required in vivo for this activation (Van Doren et al. 1991, 1992; Martinez et al. 1993). Thus, it is clear that ac and sc are active as transcriptional regulators throughout the proneural cluster, though $a c$ is the only direct regulatory target of these proteins to be identified thus far (Van Doren et al. 1991, 1992).

The neurogenic group of genes is broadly defined as those that are required to restrict the expression of the SOP fate to a single cell within the proneural cluster, a process that involves local inhibitory cell-cell interactions. Two members of the neurogenic gene family, Notch and Delta, encode transmembrane proteins that appear to function as a receptor-ligand pair in these inhibitory interactions (Fehon et al. 1990; Heitzler and Simpson 1991, 1993; Fortini and Artavanis-Tsakonas 1993). The products of other genes of the neurogenic class may be components of an intracellular signal transduction pathway downstream of the Notch receptor. These include the cytoplasmic serine/threonine kinase encoded by shaggy (Ruel et al. 1993), as well as a number of nuclear proteins that may function as transcriptional effectors of the inhibitory signal. Some of the neurogenic genes encode sequence-specific DNA-binding proteins, including Suppressor of Hairless (Furukawa et al. 1991, 1992; Schweisguth and Posakony 1992; Tun et al. 1994) and the Enhancer of split [E(spl)] gene complex (Klämbt et al. 1989; Delidakis and Artavanis-Tsakonas 1992; Knust et al. 1992), which contains seven transcription units for bHLH proteins that appear to act as transcriptional repressors.

Besides these clearly defined neurogenic genes, genetic and other evidence implicates certain other loci in the proper selection of the SOP within the proneural cluster. One of the non-bHLH genes of the $E(s p l)$ complex, $m 4$, encodes a 152-amino-acid protein of unknown function (Klämbt et al. 1989). E(spl)m4 transcripts accumulate in the embryonic neuroectoderm in a pattern that is indistinguishable from that of the $E$ (spl) bHLH gene transcripts, suggesting that it may have some function in the separation of neural and epidermal cell fates (Knust et al. 1987b; Schrons et al. 1992). Genetic experiments are also consistent with a possible role for $m 4$ in this process (Schrons et al. 1992). Dominant gain-of-function alleles of Bearded (Brd) yield a highly penetrant bristle "tufting" phenotype that results from the commitment of multiple cells within the proneural cluster to the SOP fate (M.W. Leviten and J.W. Posakony, in prep.). We have found recently that the predicted protein products of $\mathrm{Brd}$ and $E(s p l) \mathrm{m} 4$ share sequence and structural similarity, suggesting that they have related or overlapping functions (M.W. Leviten and J.W. Posakony, in prep.). Finally, the scabrous (sca) gene, which encodes a secreted protein (Baker et al. 1990), is expressed in the proneural clusters of the wing imaginal disc and is required for normal singularization of some adult bristles (Mlodzik et al. 1990; Lindsley and Zimm 1992).

Several members of the neurogenic gene family, including Notch (Cagan and Ready 1989), Delta (Parody and Muskavitch 1993), and E(spl) (Knust et al. 1987a; Tietze et al. 1992), are known to have important functions during the development of the compound eye of Drosophila, indicating that this process involves inhibitory cell-cell signaling events similar to those that take place during external sensory organ development. In both systems, these inhibitory interactions serve to restrict the expression of particular cell fates among two or more competent cells. In addition, $s c a$ is required nonautonomously within the R8 photoreceptor cell of most ommatidia to inhibit neighboring retinal cells from adopting this fate (Baker et al. 1990). Cells just anterior to the morphogenetic furrow of the eye imaginal disc appear to be part of a proneural territory that is analogous to the proneural clusters of the wing disc. $a c$ and $s c$ are not expressed in the early developing retina, and it is clear that they do not act as the proneural regulators for photoreceptors. Instead, this function is supplied by ato, which is expressed in a stripe on the anterior edge of the morphogenetic furrow (Jarman et al. 1994).

In this paper we provide evidence that the proneural proteins ac and sc directly activate several genes in the proneural clusters of the wing imaginal disc that are known or thought to play a role in the cell-cell signaling process termed lateral or mutual inhibition, by which the expression of the SOP fate is restricted to single cells. We show that these target genes are expressed in a proneural cluster pattern in the wing disc in an $a c$-sc-dependent fashion; that the proximal promoter regions of these genes contain one or more high-affinity binding sites for $\mathrm{da} / \mathrm{ac}, \mathrm{da} / \mathrm{sc}$, and $\mathrm{da} / \mathrm{da}$ protein complexes; that these binding sites define a novel extended E-box consensus sequence; and that these binding sites are essential in vivo for the expression of reporter genes in proneural clusters.

\section{Results}

ac-sc activity is required for the expression of multiple genes in imaginal disc proneural clusters

Using in situ hybridization to imaginal discs of late third-instar larvae, we investigated the spatial patterns of expression of a number of genes that are known or are likely to play a role in adult sensory organ development. As shown in Figure 1C,G,K,O, we have identified four 
Singson et al.

Figure 1. Spatial distribution of $s c$ and acsc target gene transcripts in wing and eyeantennal imaginal discs of late third-instar larvae. Whole-mount preparations were hybridized in situ with digoxygenin-labeled antisense RNA probes for $s c(A, B)$, Brd $(C-F), E(s p l) m 7(G-J), E(s p l) m 8(K-N)$, $E(s p l) m 4(O-R)$, and $s c a(S-V)$. Wing discs are shown with the presumptive anterior wing margin to the left, and the future ventral wing surface at the top. Eye-antennal discs are shown with anterior at the top. Pattern of accumulation of $s c$ transcripts in wild-type wing $(A)$ and eye-antennal $(B)$ imaginal discs is shown for comparison. Expression of the indicated genes in external sensory organ proneural clusters of the wing disc $(C, G, K, O, S)$ is abolished in discs lacking $a c$ and $s c$ function $\mid s c^{10-1} / Y$; $D, H, L, P, T)$. In contrast, expression of these genes in the antennal disc and in the retinal field of the eye disc $(E, I, M, Q, U)$ appears unaffected in discs lacking $a c$ and $s c$ function $(F, I, N, R, V)$. Arrows indicate the positions of clusters of cells that accumulate $E(s p l) m 4$ transcripts in the head capsule portion of wild-type eye discs ( $Q)$ but not of eye discs lacking $a c$ and $s c$ function $(R)$; these appear to be precursors to the vibrissae.

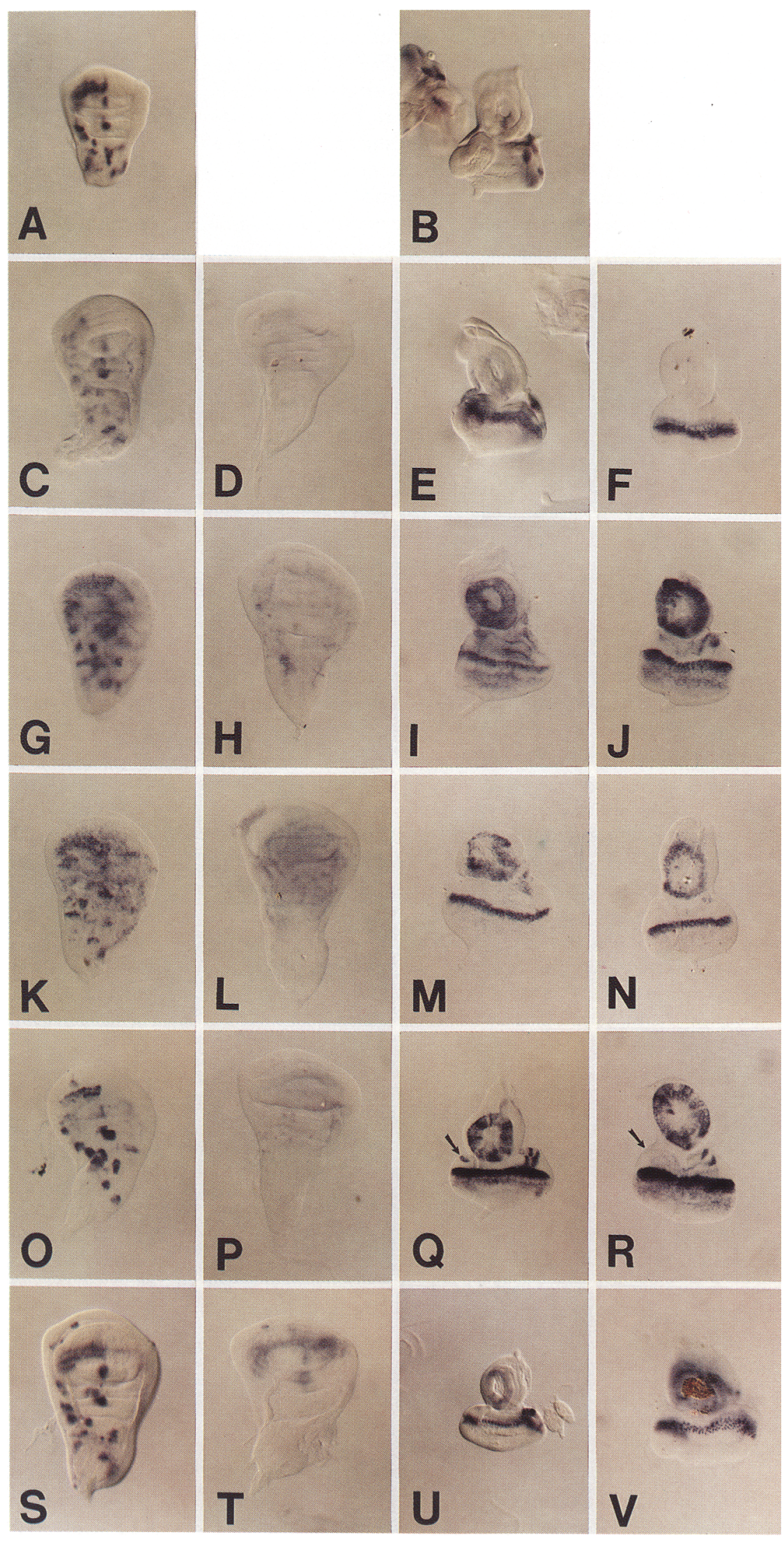


genes [Brd, E(spl)m4,E(spl)m7, and $E(s p l) m 8]$, the transcripts of which accumulate in the wing disc in a pattern very similar to that of the proneural regulators $a c$ and $s c$ (Fig. 1A), the localized expression and activity of which define the proneural clusters of potential SOP cells $\mid \mathrm{Cu}-$ bas et al. 1991; Skeath and Carroll 1991). Hinz et al. (1994) have also reported the wing disc expression pattern of $E(s p l) m 8$. In addition, Mlodzik et al. (1990) have shown previously that a fifth gene, $s c a$, is also expressed in this same proneural cluster pattern (Fig. 1S).

All five of these genes are also expressed in the eyeantennal imaginal disc (Fig. 1E,I,M,Q,U; Baker et al. 1990; Mlodzik et al. 1990). The most notable feature of this expression is a stripe of accumulated transcript in the vicinity of the morphogenetic furrow of the eye disc. The exact pattern of retinal field expression is distinctive for each gene (Fig. 1) and will not be analyzed in detail here. Nevertheless, the presence of their transcripts near the furrow is consistent with the known or suspected roles of these genes in early cell fate decisions in ommatidial development, particularly those involving cell-cell interaction (see introductory section). A second important aspect of the eye-antennal disc expression of these genes is the accumulation of transcript in a ring-shaped region of the antennal disc that includes the anlage of Johnston's organ, a large chordotonal organ. Finally, all five genes are expressed in groups of potential SOPs in the nonretinal border regions of the eye disc that give rise to the head capsule (see especially Fig. 1Q).

The similarity of the wing disc expression patterns of these five genes to those of the ac and sc proteins, which are known to function as transcriptional activators in auto- and cross-regulation in proneural clusters (Van Doren et al. 1992; Martinez et al. 1993), suggested that the former might be direct or indirect targets of $a c-s c$ regulation. We tested the $a c$-sc dependence of the expression of these candidate target genes by examining their pattern of transcript accumulation in imaginal discs from larvae carrying the $s c^{10-1}$ mutation, which inactivates both $a c$ and $s c$. Figure 1D,H,L,P,T shows that, for all five of these genes, the proneural cluster pattern of transcript distribution in wing discs is lost in $s c^{10-1}$ discs. This result indicates that $a c-s c$ activity is required to activate the normal expression of these genes in wing disc proneural clusters. In contrast, the patterns and levels of transcript accumulation in the retinal field and antenna appear unaffected in the $s c^{10-1}$ background (Fig. $1 F, J, N, R, V \mid$, indicating that transcriptional activation of the five genes in these territories is under $a c$-sc-independent control. We also find that certain of the proneural clusters at the margin of the eye disc express these genes under $a c$-sc control, whereas expression in other clusters is $a c$-sc-independent (Fig. 1Q,R).

\section{Proneural protein complexes bind in vitro to specific sites in the proximal promoter regions of putative ac-sc target genes}

The genetic results presented thus far demonstrate that $a c$-sc activity is required for the correct expression of
$B r d, E(s p l) m 4, E(s p l) m 7, E(s p l) m 8$, and sca in proneural clusters of the wing imaginal disc. However, these experiments do not address the question of whether $a c$ and $s c$ are direct transcriptional activators of these genes. We first approached this problem by attempting to identify, in the upstream regions of the candidate target genes, specific in vitro binding sites for the proneural bHLH proteins.

The specific binding sites that have been identified previously for bHLH activator proteins include a common core sequence (CANNTG) called the E box. In particular, a subset of E-box sequences conforming to the more restricted consensus CAG(G/C)TG represent highaffinity in vitro binding sites for $\mathrm{da} / \mathrm{da}, \mathrm{da} / \mathrm{ac}$, and da/sc protein complexes (Cabrera and Alonso 1991; Van Doren et al. 1991; Jarman et al. 1993) and, where tested, these sites function in vivo to mediate transcriptional activation by da, ac, and sc (Cabrera and Alonso 1991; Van Doren et al. 1992; Martinez et al. 1993). We inspected the $5^{\prime}$-flanking sequences of the five candidate target genes for occurrences of the E-box consensus. Table 1 shows that the proximal upstream regions of all of these genes contain either one $[B r d, E(s p l) m 8, s c a]$ or two $[E(s p l) m 4, E(s p l) m 7]$ E-box sequences with a GG or GC core, as well as one or more other E boxes (Fig. 2). Interestingly, with the exception of the $E(s p l) \mathrm{m} 7$ gene, the GG/GC-core E boxes are the most proximal to the transcription start site, even in genes (such as $\mathrm{Brd}$ ) with multiple upstream E boxes (Fig. 2).

We tested the ability of the proneural da, ac, and sc proteins, individually and in pairwise combination, to bind to a selected subset of these sites in vitro, using purified full-length glutathione $S$-transferase (GST) fusion proteins in an electrophoretic mobility shift assay (EMSA) with labeled E-box-containing oligonucleotides. The results are summarized in Table 1 . Figure 3A shows that all of the probes containing E boxes with GG [Brd $\mathrm{E} 1, \mathrm{E}(\mathrm{spl} \mid \mathrm{m} 7 \mathrm{E} 2$ and E3, sca E1] or GC [E(spl|m8 E1] cores are strongly bound in vitro by the $\mathrm{da}+\mathrm{ac}$ and $\mathrm{da}+\mathrm{sc}$ combinations and less well by the da protein alone. In contrast, very little binding is detectable in this assay with ac alone, sc alone, or the ac + sc combination, and no binding is observed with the GST protein alone. Shorter autoradiographic exposures of the gels shown in Figure 3A (data not shown) indicate that the major shifted complex observed with the $\mathrm{da}+\mathrm{ac}$ and $\mathrm{da}+\mathrm{sc}$ combinations has a greater mobility than the complexes observed with da alone, consistent with the lower relative molecular masses of ac and sc compared with da. We interpret this to mean that $\mathrm{da} / \mathrm{ac}$ and $\mathrm{da} / \mathrm{sc}$ hetero-oligomeric complexes are principally responsible for the DNA-binding activity observed with these protein combinations (Cabrera and Alonso 1991; Van Doren et al. 1991). Similarly, the mobility of the complexes formed weakly on the $\mathrm{E}(\mathrm{spl}) \mathrm{m} 8 \mathrm{E} 1$ probe by sc and the ac + sc combination is consistent with binding by sc homo-oligomers and ac/sc hetero-oligomers (Jiang and Levine 1993).

Both direct binding and competition assays demonstrate that the strong binding activities of the proneural 
Table 1. Alignment of E-box sequences in ac-sc target gene promoters and summary of in vitro DNA-binding and competition experiments

\begin{tabular}{|c|c|c|c|c|c|c|}
\hline \multirow[b]{2}{*}{ E box } & \multirow{2}{*}{\multicolumn{2}{|c|}{ Sequence }} & Binding & \multicolumn{3}{|c|}{ Competition } \\
\hline & & & mut & & & mut \\
\hline Brd & $\begin{array}{l}\text { E1' }(-88) \\
\text { E2' }(-188) \\
\text { E3' }(-499) \\
\text { E4' }(-672) \\
\text { E5' }(-834) \\
\text { E6' }(-877) \\
\text { E7' }(-965) \\
\text { E8' }(-999) \\
\text { E9' }(-1039) \\
\text { E10' }(-1117)\end{array}$ & $\begin{array}{l}\text { CGCAGGTGTT } \\
\text { TGCACGTGTC } \\
\text { AACACATGTT } \\
\text { CACACTTGTT } \\
\text { ACCACTTGGA } \\
\text { CACACTTGTG } \\
\text { GGCACTTGTA } \\
\text { TCCAGTTGCA } \\
\text { TCCACTTGGG } \\
\text { AGCACTTGAA }\end{array}$ & $\begin{array}{c}++++ \\
+ \\
+1- \\
-\end{array}$ & - & $\begin{array}{c}++++ \\
+++ \\
++ \\
-\end{array}$ & - \\
\hline$E(s p l) m 7$ & $\begin{array}{l}\text { E1 }(-41) \\
\text { E2 }(-128) \\
\text { E3 }(-226) \\
\text { E4 }(-342)\end{array}$ & $\begin{array}{l}\text { GGCACGTGCA } \\
\text { CGCAGGTGGT } \\
\text { CGCAGGTGTG } \\
\text { CCCATTTGAA }\end{array}$ & $\begin{array}{l}++++ \\
++++\end{array}$ & - & $\begin{array}{c}+++ \\
++++\end{array}$ & - \\
\hline$E(s p l) m 8$ & $\begin{array}{l}\text { E1 }(-138) \\
\text { E2 }(-462)\end{array}$ & $\begin{array}{l}\text { TGCAGCTGTT } \\
\text { AGCAGTTGAA }\end{array}$ & $\stackrel{++++}{-}$ & - & ++++ & - \\
\hline$E(s p l) m 4$ & $\begin{array}{l}\text { E1' }(-162) \\
\text { E2 }(-250) \\
\text { E3 }(-492)\end{array}$ & $\begin{array}{l}\text { GGCAGGTGTG } \\
\text { AACAGGTGCG } \\
\text { AACACGTGTG }\end{array}$ & & & & \\
\hline sca & $\begin{array}{l}\text { E1 }(-174) \\
\text { E2' }(-416) \\
\text { E3' }(-470) \\
\text { E4 }(-578)\end{array}$ & $\begin{array}{l}\text { GGCAGGTGGC } \\
\text { GACACATGG } \\
\text { GGCAGATGTT } \\
\text { GACATTTTGC }\end{array}$ & ++++ & - & ++++ & - \\
\hline
\end{tabular}

All E-box sequences (CANNTG, bold type) found in the sequenced upstream regions of the indicated genes are listed, along with two flanking nucleotides on each side. E boxes are numbered in order of increasing distance upstream of the transcription start site (negative numbers, in bp; see Fig. 2); sequences read from the antisense strand are indicated by a prime ('). The two core nucleotides of each $E$ box are underlined; $E$ boxes with a GG or GC core are given bold italic designations (e.g., Brd E1). The relative strength of da/ac and da/sc binding to each wild-type (CANNTG) or mutant (AANNTT) site tested, as well as the ability of each tested site to compete for binding to the wild-type Brd El site, is summarized from Fig. $3 .(++++)$ Strongest binding or competition activity; $|-|$ no detectable binding or no ability to compete specifically for binding to Brd El. Sequence data for $E(\mathrm{spl}) \mathrm{m} 8$ are from Klambt et al. (1989); data for $s c a$ are from Mlodzik et al. (1990). Nucleotide sequences of the 5'-flanking regions of $\mathrm{Brd}, E(\mathrm{spl}) \mathrm{m} 7$, and $E$ (spl)m4 (this paper) have been deposited in the GenBank data base.

proteins on the GG/GC-core E-box probes are sequencespecific. Mutant oligonucleotides in which the E-box sequence $\mathrm{CAG}(\mathrm{G} / \mathrm{C}) \mathrm{TG}$ is changed to $\mathrm{AAG}(\mathrm{G} / \mathrm{C}) \mathrm{TT}$ are not bound detectably by the proneural proteins (either alone or in pairwise combination) in the EMSA (Fig. 3C). Similarly, wild-type but not mutant GG/GC-core E-box oligonucleotides are effective competitors in the EMSA for da/sc binding to the Brd El probe (Fig. 3D). These experiments show that the E-box nucleotides in the Brd $\mathrm{E} 1, \mathrm{E} / \mathrm{spl} / \mathrm{m} 7 \mathrm{E} 2$ and $\mathrm{E} 3, \mathrm{E} / \mathrm{spl} / \mathrm{m} 8 \mathrm{E} 1$, and sca $\mathrm{E} 1$ probes constitute at least part of the sequence required for the binding of proneural proteins in vitro.

We also tested the interaction of proneural proteins with five probes that contain representative $\mathrm{E}$ boxes with core sequences other than GG or GC [four from $\mathrm{Brd}$ (E2, $\mathrm{E} 3, \mathrm{E} 4$, and $\mathrm{E} 8$ ) and one from $E(\mathrm{spl}) \mathrm{m} 8$ (E2)]. In these cases, binding activity in the EMSA was very low compared with that observed with GG/GC-core E-box probes of comparable specific activity (Fig. 3B; Table 1). Of the five sites, the highest binding activity was obtained with the Brd E2 and E3 probes; very little binding was apparent with the Brd E4, Brd E8, and E/spl/m8 E2 probes. In all cases, only the da protein alone, and the da $+\mathrm{ac}$ and $\mathrm{da}+\mathrm{sc}$ combinations, gave detectable binding; none was observed with ac alone, sc alone, the ac + sc combination, or GST alone. A competition assay using da/sc binding to the Brd El probe (Fig. 3D) corroborates these results. None of the four probes tested (Brd E2, E3, E4, and E8) is as effective a competitor as the wild-type Brd E1 probe itself. The Brd E2 and E3 oligonucleotides exhibit moderate competitive activity while the Brd E4 and E8 probes are nearly as ineffective as the Brd El mutant probe. Taken together, these observations indicate that the CG-, CA-, CT-, and GT-core E-box sequences in the five probes studied represent binding sites of lower or much lower affinity for the proneural proteins in vitro.

An alignment of the five E-box sequences from the candidate target genes that we have shown to represent high-affinity proneural protein-binding sites is depicted in Figure 4. These sites define an extended consensus sequence, GCAGGTG/T/G)NNNYY, that is common to all except $\mathrm{E} / \mathrm{spl} / \mathrm{m} 8 \mathrm{El}$, which has a single-base mismatch within the E-box (a GC core instead of a GG core). The elements of the consensus outside the E-box hexamer (CAGGTG), including the pair of pyrimidine residues that is present 5 bases $3^{\prime}$ to the $\mathrm{E}$ box in all five sites, may influence the specificity or affinity of binding. Interestingly, the most proximal E-box sequences upstream of the transcription start sites of $a c$ [T5E1; Van

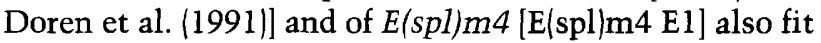
this consensus exactly (Fig. 4). Like the GG/GC-core E-boxes considered here, the T5E1 site has been shown previously to bind both da alone and da/ac and da/sc hetero-oligomers with high affinity (Cabrera and Alonso 1991; Van Doren et al. 1991). Finally, the second most proximal $\mathrm{E}$ box $5^{\prime}$ to the transcription start site of $E$ (spl)my (Delidakis and Artavanis-Tsakonas 1992) is likewise an exact match to the consensus, except that like $\mathrm{E} / \mathrm{spl} / \mathrm{m} 8 \mathrm{E} 1$, it has a GC core sequence. We have observed recently that $E(s p l) m \gamma$ is expressed in the wing disc in an $a c$-sc-dependent manner (J. Kavaler and J.W. Posakony, unpubl.).

\section{Proximal promoter fragments of the $\mathrm{Brd}$ and $\mathrm{E} / \mathrm{spl} / \mathrm{m} 7$ genes direct ac-sc-dependent expression of $a$ reporter gene in a proneural cluster pattern}

The results presented in Figure 3 establish that four of the five candidate target genes contain, in positions close to their transcription start sites, specific high-affinity in vitro binding sites for proneural proteins. This finding suggested that proximal promoter fragments from these genes might be sufficient to direct $a c$-sc-dependent ex- 


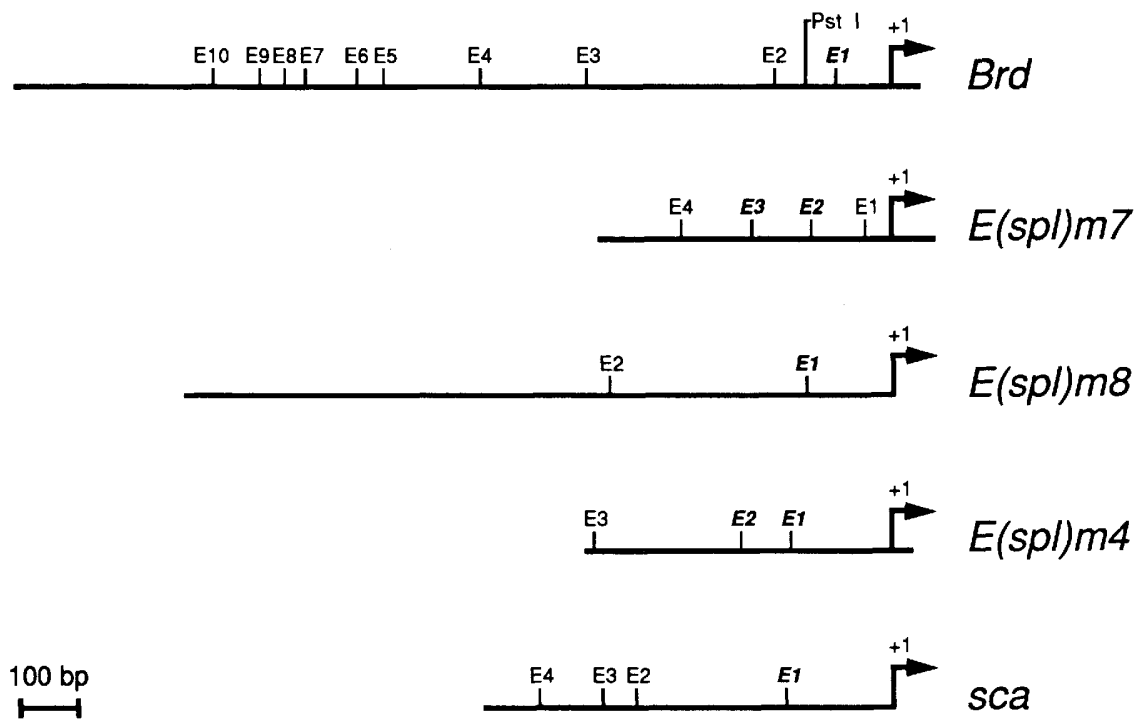

Figure 2. Diagrammatic representation of 5 -flanking regions of ac-sc target genes, showing the relative positions of E-box sequences. Scale is shown at lower left. E boxes are designated by number in order of increasing distance from the transcription start site (arrows at +1 ). E boxes with a GG or GC core are indicated in bold italics. The PstI site indicated in the 5' flanking region of $B r d$ was used in the construction of pBrd 0.19-LacZ (see Materials and methods|. An alignment of all E-box sequences represented here is given in Table 1. Sequence data for $E(s p l) m 8$ are from Klämbt et al. (1989); data for sca are from Mlodzik et al. (1990). Nucleotide sequences of the $5^{\prime}$-flanking regions of $\mathrm{Brd}$, $E(s p l) m 7$, and $E(s p l) m 4$ (this paper) have been deposited in the GenBank data base. pression in imaginal discs. We tested this possibility by establishing lines of transgenic flies carrying one of three fusion genes, in which the Escherichia coli lacZ gene is placed under the control of a $1.5-\mathrm{kb}$ promoter fragment from $B r d(-1449 \rightarrow+42$; Fig. 2), a 0.19-kb Brd fragment $(-144 \rightarrow+42$; Fig. 2$)$, or a $0.5-\mathrm{kb}$ promoter fragment from $E$ (spl)m $7(-478 \rightarrow+65$; Fig. 2). Both of the Brd constructs include the high-affinity $\mathrm{E} 1$ proneural protein binding site, whereas the $E(s p l) m 7$ construct includes both the E2 and E3 high-affinity sites.

Figure $5(A, G, J)$ shows that all three of these constructs are expressed in a proneural cluster pattern in the late third-instar wing disc. The similarity of the expression patterns of the Brd $1.5-\mathrm{kb}$ and $0.19-\mathrm{kb}$ constructs is striking and indicates that a promoter fragment containing only the high-affinity Brd E1-binding site is sufficient to direct reporter gene expression in the proneural cluster pattern, though other sequences within this fragment may be required for this activity.

All three of the promoter-reporter fusion genes exhibit a higher level of expression in the presumptive SOP than in the remaining cells of the proneural cluster, consistent with the higher level of ac and sc protein in SOPs (Skeath and Carroll 1991). While this behavior is clearly observed for the endogenous sca gene (Mlodzik et al. 1990), it is not certain from our in situ hybridization data whether the other genes are normally up-regulated in the SOP. It would perhaps be surprising for the $E(s p l) m 7$ and $m 8$ genes to be expressed at higher levels in the SOP, given that their wild-type function is to antagonize the SOP cell fate within the proneural cluster. We think it likely that specific mechanisms normally operate to regulate the SOP expression or activity of such inhibitory ac-sc target genes. These might include transcriptional repression (requiring cis-regulatory sites not present in our promoter constructs) (Kramatschek and Campos-Ortega 1994) or post-transcriptional controls on RNA or protein stability (to which $l a c Z$ mRNA and protein would most likely not be responsive).
The distinct regulation of $B r d$ and $E(s p l) m 7$ expression in the antenna and in the retinal field of the eye versus the proneural clusters of the wing disc (Fig. 1) is emphasized further by the activities of the promoter-reporter constructs in the eye-antennal disc. The Brd $1.5-\mathrm{kb}$ promoter fragment reproducibly drives a high level of $l a c Z$ expression near, and posterior to, the morphogenetic furrow (Fig. 5D). This pattern mimics that of the endogenous Brd transcript (Fig. IE). In contrast, only a fraction of the $B r d 0.19-\mathrm{kb}$ or the $E(s p l) \mathrm{m} 7$ promoter fusion lines exhibit any detectable expression in the retinal field, and this is very weak by comparison (data not shown). This result implies that the cis-regulatory elements that direct expression of $B r d$ and $E(s p l) m 7$ in the retina are at least partially distinct from those that control the activation of these genes in wing disc proneural clusters.

We tested whether the activity of the three promoterreporter fusion genes is dependent on the activity of the proneural regulators ac and $\mathrm{sc}$ by introducing them into the $s c^{10-1}$ background. As shown in Figure $5(\mathrm{~B}, \mathrm{H}, \mathrm{K}), 1 a c Z$ expression from these constructs in wing disc proneural clusters is reduced severely or abolished in the absence of $a c$-sc function. In contrast, the $B r d 1.5-\mathrm{kb}$ promoter remains active at apparently normal levels in the retinal field and antenna of $s c^{10-1}$ eye-antennal discs (Fig. 5E). Thus, the pattern of $a c$-sc dependency exhibited by the expression of the endogenous genes (Fig. 1C-J) is mimicked by the Brd and $E(s p l) m 7$ promoter-lacZ fusion genes.

Mutation of binding sites for proneural proteins abolishes activation of the $\mathrm{Brd}$ and $\mathrm{E}(\mathrm{spl}) \mathrm{m} 7$ promoters in proneural clusters

Because proximal promoter fragments from $B r d$ and $E(s p l) m 7$ are capable of directing $a c$-sc-dependent expression in wing disc proneural clusters, a critical question was whether the $\mathrm{da} / \mathrm{ac} / \mathrm{sc}$-binding sites that we had identified in these promoters are necessary for this ac- 

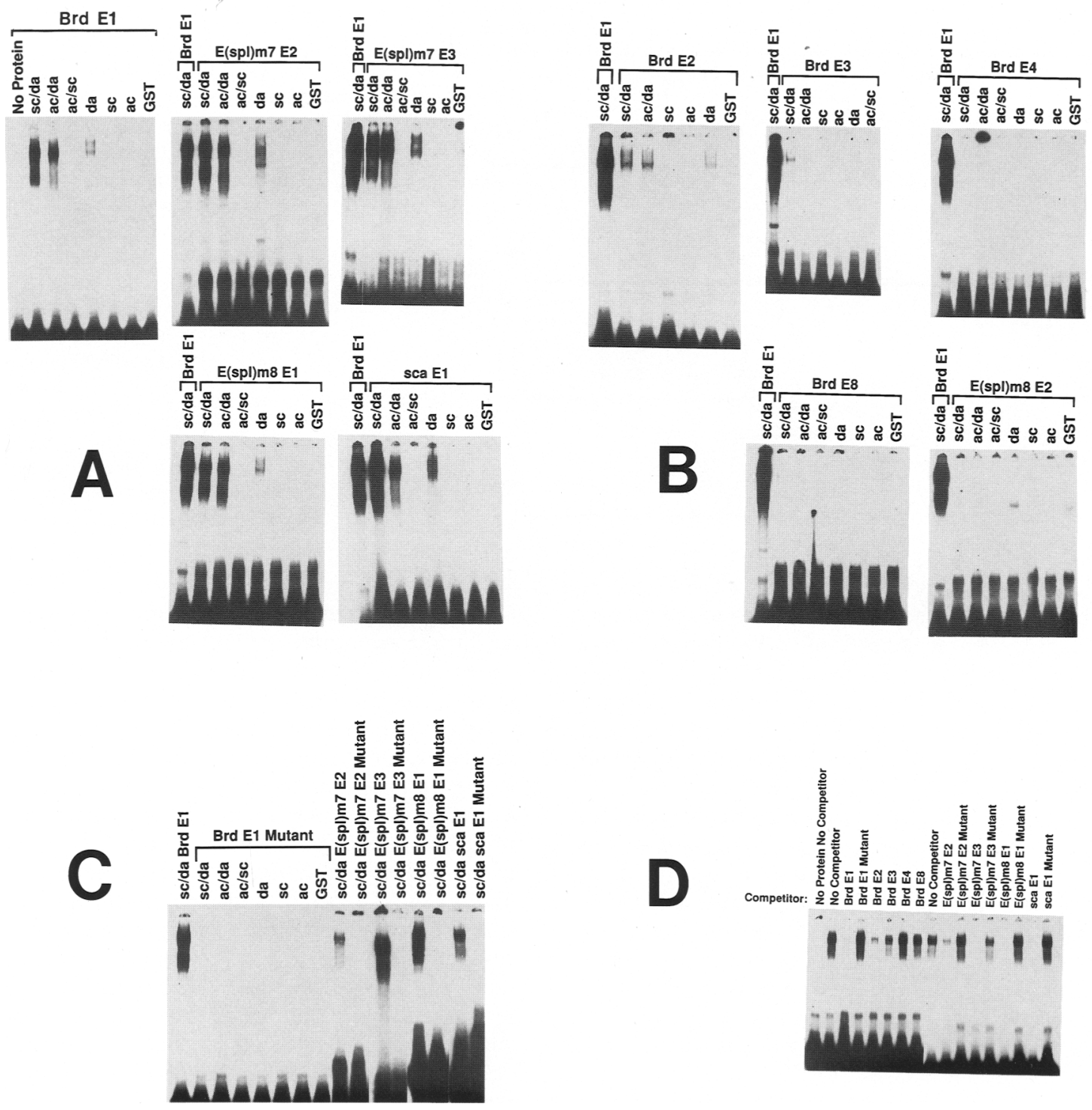

Figure 3. Electrophoretic mobility shift assays of $\mathrm{da}$, ac, and $\mathrm{sc}$ binding to $\mathrm{E}$ box sequences in the proximal promoters of candidate target genes. $(A)$ Oligonucleotide probes containing E boxes that conform to the consensus CAG(G/C)TG (GG- or GC-core E boxes; see Table 1) are bound efficiently by da/ac and da/sc hetero-oligomeric complexes, as well as by da homo-oligomers. ac alone, sc alone, and the ac + sc combination fail to show significant binding activity with these probes. $(B)$ Relative to the Brd El probe, oligonucleotide probes containing E-box sequences with other than GG or GC cores (see Table 1) are bound much more weakly or not at all by da, ac, and sc, either alone or in pairwise combination. $(C)$ Binding of proneural protein complexes to oligonucleotide probes containing GGor GC-core $\mathrm{E}$ boxes requires the integrity of the E-box sequence. Mutation of the E box (CANNTG to AANNTT) completely abolishes binding of $\mathrm{da} / \mathrm{ac}, \mathrm{da} / \mathrm{sc}$, and da/da protein complexes. All individual and pairwise combinations of the da, ac, and sc proteins were tested, though results for some combinations are not shown for the $\mathrm{E}(\mathrm{spl}) \mathrm{m} 7 \mathrm{E} 2, \mathrm{E} / \mathrm{spl} \mid \mathrm{m} 7 \mathrm{E} 3, \mathrm{E} / \mathrm{spl}) \mathrm{m} 8 \mathrm{E} 1$, and sca E1 sites. $(D) \mathrm{Binding}$ of proneural proteins to the Brd El probe is efficiently competed by probes containing strong binding sites (see $A$ ), but poorly or not at all by probes containing weaker or mutant binding sites $($ see $B, C)$. Binding and competition activity of weaker sites may correlate with their similarity to high-affinity sites such as Brd E1 [e.g., the Brd E2 site represents only a 1-bp change from Brd E1 (GCACGTGT vs. GCAGGTGT)]. Competition by weaker binding sites was observed by using a 200 -fold excess of competitor and poly[d(A,T)] as the nonspecific competitor (see Materials and methods).

tivity. We constructed three promoter-reporter fusion genes identical to those described above but including 2-bp mutations that change the Brd E1 and E(spl $/ \mathrm{m} 7 \mathrm{E2}$ and E3 E-box sequences from CAGGTG to CCGGTT. Figure $5(\mathrm{C}, \mathrm{I}, \mathrm{L})$ shows that the mutant promoters fail to be activated in the proneural clusters of the third-instar wing imaginal disc, though the $B r d 1.5-\mathrm{kb}$ promoter fragment remains capable of directing apparently normal levels of expression in the antenna and retinal field of the eye-antennal disc (Fig. 5F). This result demonstrates 
Brd E1' (-88)

E(spl)m7 E2 (-128)

E(spl)m7 E3 (-226)

$E(s p l) m 8$ E1 (-134)

sca E1 (-174)

CONSENSUS

ac (T5) E1 (-58)

$E(s p l) m 4$ E1' (-162)

CAACAAAAACGGCAGGTGTGTTTTTCGAA

E(spl)m $\gamma$ E2 (-375) ATCTAGAAACGGCAGCTGTTCGCTCTGCA

Figure 4. Sequence alignment and consensus of proximal proneural response elements (PPREs). Sequences surrounding highaffinity $\mathrm{da} / \mathrm{ac} / \mathrm{sc}$ binding sites from the proximal promoter regions of the target genes $B r d, E(s p l) m 7, E(s p l) m 8$, and sca are aligned by their E-box nucleotides. These sequences define the extended consensus shown. Nucleotides in each site that match the consensus surrounding the E box are shown in bold; the pair of pyrimidines $3^{\prime}$ to the $\mathrm{E}$ box in all sites is underlined. The location of each site is indicated in parentheses by the position of the first $C$ residue of the consensus (in bp upstream of the transcription start site). As shown below the consensus, the most proximal E-box site in the promoter of the $a c$ gene itself [T5E1; Van Doren et al. (1991)] matches the PPRE consensus exactly. The most proximal E-box site in $E(s p l) m 4$ (E1; see Fig. 2) also matches the PPRE consensus exactly; $E(s p l) m 4$ expression in external sensory organ proneural clusters is dependent on $a c$ and $s c$ activity (see Fig. 1O-R). The second most proximal E-box site in $E(s p l) m \gamma$ (which encodes a bHLH protein) is, like $\mathrm{E}$ (spl)m8 E1, a 1-bp variant of the PPRE consensus (a GC-core E box instead of a GG-core). In addition to the PPRE consensus shown, note the almost complete lack of $A$ residues in the two positions $5^{\prime}$ of the consensus and in the consensus positions indicated by NNN. Sequence data for $E(\mathrm{spl}) \mathrm{m} 8$ are from Klämbt et al. (1989); for sca, Mlodzik et al. (1990); for $E(s p 1) m \gamma$, Delidakis and Artavanis-Tsakonas (1992). Nucleotide sequences of the $5^{\prime}$-flanking regions of $B r d, E(s p l) m 7$, and $E(s p l) m 4$ (this paper) have been deposited in the GenBank data base.

that the high-affinity proneural protein binding sites in the $B r d$ and $E(s p l) m 7$ promoters are specifically required for the normal activation of these promoters in wing disc proneural clusters.

\section{Discussion}

Identification of direct downstream targets of ac and sc in wing disc proneural clusters

The evidence presented in this paper strongly supports the conclusion that the $B r d, s c a, E(s p l) m 4, E(s p l) m 7$, and $E(s p l) m 8$ genes are directly activated in proneural clusters of the late third-instar wing imaginal disc by protein complexes that include the ac and sc bHLH proteins. Transcripts of these genes accumulate in a spatial pattern in the wing disc that is very similar to the proneural cluster pattern of ac and sc activity, and their expression is reduced severely or abolished in $a c^{-} s c^{-}$mutant discs (Fig. 1). The proximal promoter regions of all of these genes contain one or two specific, high-affinity binding sites for the proneural proteins $\mathrm{da}$, ac, and sc (Figs. 2 and 3; Table 1). Fragments of the $B r d$ and $E(s p l) \mathrm{m}^{7}$ promoters that include these sites are sufficient to direct $a c$-sc-dependent expression of a reporter gene in wing disc proneural clusters (Fig. 5). Finally, mutation of the highaffinity $\mathrm{da} / \mathrm{ac} / \mathrm{sc}$ binding sites in these two promoters reduces severely or abolishes reporter gene activity in proneural clusters (Fig. 5).

These data do not strictly rule out the possibility that another transcription factor, the expression or activity of which is $a c$-sc-dependent, is actually the direct activator of these genes in vivo and that ac and sc act indirectly. The activity of the hypothetical factor would be dependent on the proneural protein-binding sites that we have shown are required in vivo for the activities of the $\mathrm{Brd}$ and $E(s p l) m 7$ promoters. For example, ac and sc could control the expression of a factor that potentiates transcriptional activation by da, so that da alone would be the direct activator. However, we believe the simplest interpretation of the evidence is that ac and sc participate directly in transcriptional activation of the genes that we have studied.

Previous experiments indicate that ac and sc are highly active in DNA binding in vitro and in transcriptional activation in yeast and tissue culture cells only in the presence of da (Cabrera and Alonso 1991; Van Doren et al. 1991, 1992) or a non-bHLH partner such as dorsal (Gonzalez-Crespo and Levine 1993; Jiang and Levine 1993). These findings, along with the demonstration that da protein is apparently present in all cells of the wing imaginal disc (Cronmiller and Cummings 1993), motivate our working hypothesis that $\mathrm{da} / \mathrm{ac}$ and $\mathrm{da} / \mathrm{sc}$ heterooligomers are the active complexes in mediating the transcriptional regulatory functions of ac and sc in imaginal disc proneural clusters. However, it is possible that post-translational modifications (for example) allow ac and sc to activate transcription in vivo independently of da or other factors.

Proximal promoter regions of ac-sc target genes contain high-affinity binding sites with a characteristic extended E-box consensus

We have found that the proximal upstream regions of ac-sc target genes contain either one or two E-box sites to which ac and sc, in combination with da, bind with high affinity in vitro; the da protein alone also binds to these sequences. Three features of the binding sites are noteworthy. The first is their location. In all six of the ac-sc proneural cluster target genes we have defined (including $a c$ itself), a high-affinity binding site is found relatively close to the TATA box and transcription start site [between $-58(a c)$ and $-174(s c a)$. With one exception $[E(s p l) m 7]$, the high-affinity site or sites are the most proximal E box (CANNTG) consensus sequences found in the promoter. Second, all of the high-affinity binding sites belong to a subset of $\mathrm{E}$ boxes described by the consensus RCAG(G/C)TG; E boxes with other than a GG or GC core are bound much more weakly by da, ac, 

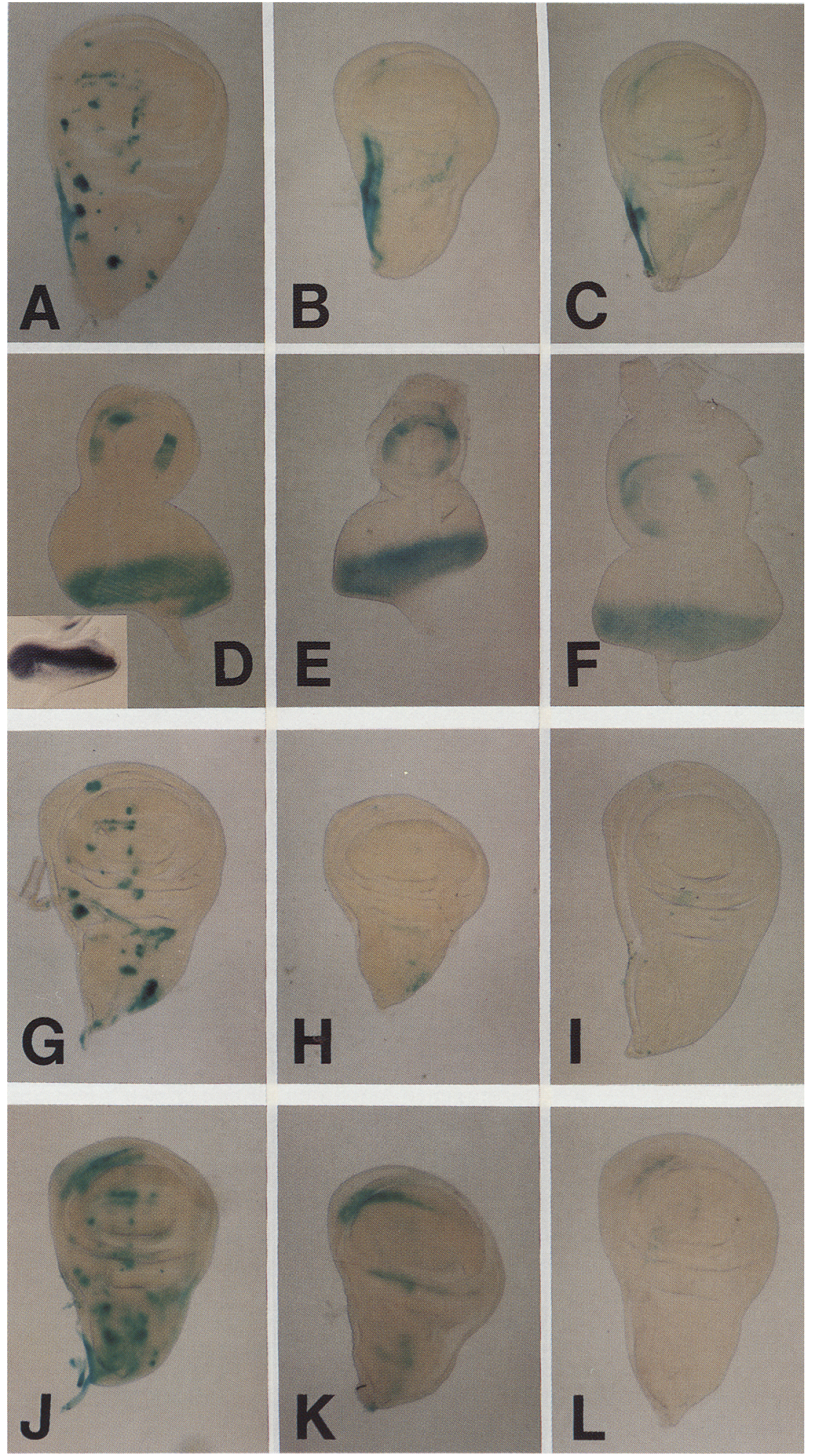

Figure 5. Promoter-reporter fusion genes require $\mathrm{da} / \mathrm{ac} / \mathrm{sc}$ binding sites for expression in external sensory organ proneural clusters. All panels show imaginal discs from late third-instar larvae stained for $\beta$-galactosidase activity. $\mathrm{Brd}$ promoter fragments of 1.5 or $0.19 \mathrm{~kb}$ and an $E$ (spl) $m 7$ promoter fragment of $0.5 \mathrm{~kb}$ (see Fig. 2) were fused to the E. coli lacZ gene in the CaSpeRlacZ P-element transformation vector. Lines of transgenic flies carrying either the wild-type reporter constructs (P[Brd 1.5-lacZ], P[Brd 0.19-lacZ], and $\mathrm{P}[\mathrm{m} 7 \mathrm{0.5}-\mathrm{lacZ}])$, or the same constructs with their high-affinity $\mathrm{da} / \mathrm{ac} / \mathrm{sc}$ binding sites mutated (P[Brd 1.5M-LacZ), $\mathrm{P}[$ Brd 0.19M-LacZ], and $\mathrm{P}[\mathrm{m} 7 \quad 0.5 \mathrm{M}-$ LacZl; E-box sequences changed from CAGGTG to CCGGTT), were established. The wild-type constructs are expressed in a proneural cluster pattern in the wing disc: (A) P[Brd 1.5-lacZ]-1 (4 of 4 lines), (G) P[Brd 0.19-1acZ]-10 (10 of 15 lines), and $(J) P / \mathrm{m} 70.5-1 a c Z]-6$ (3 of 7 lines). The proneural cluster expression of these wildtype reporter genes is abolished in discs lacking the function of the endogenous $a c$ and $s c$ genes: $(B) s c^{10-1} / Y$; $P[B r d 1.5-1 a c Z]-$ 1/P[Brd 1.5-lacZ]-1, $(H) \mathrm{sc}^{10-1} / Y$; P[Brd $0.19-1 a c Z]-10 / P[B r d \quad 0.19-1 a c Z]-10$; and (K) $s c^{10-1} / Y ; P[m 7$ 0.5-lacZ]-6/P[m7 0.5lacZl-6. The same lack of proneural cluster expression is observed in wing discs from transgenic animals carrying the mutant promoter-reporter constructs: $(C)$ P[Brd 1.5M-lacZ]-8 (7 of 8 lines), (I) P[Brd $0.19 M-l a c Z$ ) 4 (10 of 10 lines), and $(L)$ $P(m 7 \quad 0.5 M-l a c Z)-10$ (15 of 15 lines). In contrast, construct- or insertion-specific ectopic expression is unaffected by the $s c^{10-1}$ background or by mutation of proneural protein-binding sites (e.g., $A-C$ ), and provides a control for the staining reaction. Of the three promoter fragments tested, only the $1.5-\mathrm{kb} \mathrm{Brd}$ fragment $(D$ : P[Brd 1.5-lacZ]-1) exhibits consistent expression in the retinal field of the eye-antennal disc (4 of 4 lines). This expression pattern is not detectably altered in discs lacking $a c$ and $s c$ function $\left(E: s c^{10-1} / Y\right.$; P[Brd 1.5-lacZ]-1/P[Brd 1.5-lacZ]-1) or in wild-type discs carrying the $1.5-\mathrm{kb} B r d$ promoter fragment with the high affinity da/ac-sc DNA-binding site mutated (F: $P[B r d 1.5 M-l a c Z]-8]$. $\beta$-Galactosidase staining in the retinal fields of these discs $(D-F)$ extends more posteriorly than transcript accumulation from the endogenous $\mathrm{Brd}$ gene (cf. Fig. 1E). This is likely because of the perdurance of $\beta$-galactosidase protein: When reporter gene expression is assayed using a digoxygenin-labeled antisense probe for lacZ RNA (inset in $D$ ), the observed pattern of transcript accumulation is comparable to that of endogenous Brd RNA (cf. inset in $D$ with Fig. 1E). 
and sc in vitro (Van Doren et al. 1991; Jarman et al. 1993). Finally, an alignment of the most proximal highaffinity $\mathrm{da} / \mathrm{ac} / \mathrm{sc}$ binding sites in these genes defines a novel extended E-box consensus sequence, GCAGGTG(T/G)NNNYY. In genes with more than one highaffinity da/ac/sc binding site-E(spl)m4, $E(s p l) m 7$, and $a c$-the site nearest the transcription start fits this consensus; in $E(s p l) m 7$, both sites match. We propose the name proximal proneural response element (PPRE) to refer to these particular (i.e., most proximal) sites and to the consensus sequence that they define (Fig. 4). The predictive value of this consensus is illustrated by the fact that we did not obtain the sequence of the $E(\mathrm{spl}) \mathrm{m} 4$ upstream region until after the consensus had been defined by in vitro DNA-binding studies with the other promoters.

The similarity in both location and sequence of functional da/ac/sc binding sites in such a diverse set of target genes is very likely to be of regulatory significance. It is possible that the proximity of these high-affinity sites to the TATA box serves to maximize the activating capacity of proneural protein complexes bound to them. In this case, the PPRE may not function effectively at great distances (>500 bp) from the promoter. Nevertheless, it is clear that PPREs can function in vivo in either orientation with respect to the direction of transcription [cf. Brd E1 and E(spl)m7 E2/E3]. The extended sequence restriction of the PPRE on either side of the E-box hexamer may help to confer greater specificity on the activation of these target genes by proneural proteins.

\section{Distinct cis and trans control of ac-sc target gene expression in proneural clusters and in the retina}

The results presented here indicate clearly that both the cis-regulatory elements and the trans-activators that control expression of ac-sc target genes in late third-instar wing disc proneural clusters are at least partially distinct from those that control their expression in the antenna and retinal field of the eye-antenna disc at the same stage. First, $a c$ and $s c$ are not detectably expressed in the late third-instar retina (Fig. 1B), and we have shown here that the expression of several proneural cluster target genes in the vicinity of the morphogenetic furrow is correspondingly independent of ac-sc function (Fig. 1). Second, certain proximal promoter fragments that contain high-affinity da/ac/sc binding sites and are capable of directing $a c$-sc-dependent reporter gene expression in wing disc proneural clusters give only very weak and variable expression in the retinal field of thirdinstar eye discs (data not shown). This includes both the Brd 0.19-kb fragment (Fig. 2) and the $E$ (spl)m7 $0.5-\mathrm{kb}$ fragment (Fig. 2), as well as a 0.9-kb fragment of the $a c$ promoter that contains three E-box sites required in proneural clusters for $a c$ autoregulation and cross-regulation by sc (Martinez and Modolell 1991; Van Doren et al. 1991, 1992; Martinez et al. 1993). Finally, mutation of the single high-affinity E-box site (Brd E1) in the Brd 1.5-kb promoter fragment (Fig. 2; Table 1) results in the loss of promoter activity in wing disc proneural clusters (Fig. 5A,B), but apparently does not affect its activation in the retina (Fig. 5C), although we cannot rule out the loss of a small subset of the expression pattern (e.g., a narrow anterior stripe). These last observations demonstrate that high-affinity $\mathrm{da} / \mathrm{ac} / \mathrm{sc}$ binding sites are neither necessary nor sufficient for high-level expression of ac-sc target genes in the retinal field of the third-instar eye disc.

The proneural gene ato is required for the development of both chordotonal organs and photoreceptors (Jarman et al. 1993, 1994). The predicted ato product is a bHLH protein closely related to ac and sc and when combined with $\mathrm{da}$, can bind in vitro to oligonucleotides containing a GG-, a GC-, or a GA-core E-box from the asense gene (Jarman et al. 1993). Unlike $a c$ and $s c$, ato is expressed at the anterior edge of the morphogenetic furrow in the third-instar eye disc and in a large ring-shaped territory in the antenna disc (Jarman et al. 1993, 1994). In addition, it is expressed in two small clusters of cells in the nonretinal (head capsule) portion of the eye disc. The pattern of ato transcript accumulation in these regions is quite similar to the distribution of $a c$-sc-independent transcripts from the ac-sc target genes that we have defined here, particularly $E(s p l) m 4$ and $E(s p l) m 7$ (Fig. 1). Moreover, ato activity is required for the expression of sca protein in the retina (Jarman et al. 1994). These observations raise the possibility that ato might function as a direct transcriptional activator of these genes in the retina, in Johnston's organ, and in chordotonal organs of the head capsule. If this is the case, our results suggest that ato may function through promoter-binding sites distinct from those utilized by ac and sc in proneural clusters, or that an additional factor is required for its activation of genes in the retina and the antenna.

The proneural regulators $a c$ and sc activate antagonists of the SOP cell fate in proneural clusters

One of the most important findings of our study concerns the function of the genes that are directly activated in the proneural clusters of the wing disc by the proneural regulators ac and sc. With the possible exception of $E(s p l) m 4$, genetic evidence indicates that all of the genes we have studied play a role in the process by which expression of the SOP cell fate is inhibited in all but one cell of the proneural cluster (see introductory section). This observation has important implications for our understanding of pattern formation in adult sensory organ development. It appears that $a c$ and $s c$ have two oppositely directed activities with respect to neural cell fate determination. First, they promote sensory organ development by conferring on groups of imaginal disc cells the potential to become SOPs, presumably by activating (directly or indirectly) genes required for this fate, particularly within the SOP itself. This first activity constitutes the genetically defined proneural function of $a c$ and $s c$, and includes direct auto- and cross-regulation within the proneural clusters and perhaps in the SOPs (Van Doren et al. 1991, 1992; Martinez et al. 1993). Second, ac and sc 
activate, within the proneural clusters and within SOPs, other genes that act instead to antagonize the SOP fate, apparently as part of the cell-cell signaling process referred to as lateral or mutual inhibition. These diverse regulatory functions of ac and sc are summarized in Figure 6. We conclude that $a c$ and $s c$ are not strictly proneural genes but, instead, have a complex role in establishing local conditions of gene expression in the imaginal disc epithelium that lead to the stable determination of individual cells as SOPs.

Consistent with our results, ectopic activation of genes involved in lateral inhibition has been observed previously to accompany the ectopic expression of lethal of scute, a proneural gene not normally active in imaginal discs (Hinz et al. 1994). In addition, Kramatschek and Campos-Ortega (1994) recently reported evidence that proneural genes function to activate the expression of the $E(s p l) m 5$ and $m 8$ genes in the ventral neuroectoderm of the embryo, from which the larval CNS arises. It is unclear whether this activation in the embryo is direct. Although we have shown here that $\mathrm{E} / \mathrm{spl} / \mathrm{m} 8 \mathrm{El}$ is the only high-affinity E-box-binding site for proneural proteins in the $E(s p I) m 8$ proximal promoter, Kramatschek and Campos-Ortega (1994) find that mutation of this site only slightly reduces reporter gene expression in the neuroectoderm and does not mimic the strong qualitative effect of loss-of-function mutations in proneural genes. Nevertheless, it seems likely that proneural gene-dependent regulation of certain genes involved in lateral inhibition is a common element of neurogenesis in both the embryonic ventral ectoderm and the imaginal discs.

The observations reported here offer an important addition to our understanding of the proneural cluster, the group of cells from which the single SOP is selected. Many of the genes required for the process of lateral inhibition, including Notch (Fehon et al. 1991), Delta (Kooh et al. 1993), Suppressor of Hairless (Schweisguth and Posakony 1992), Hairless (Bang and Posakony 1992), and groucho (Delidakis et al. 1991; A.G. Bang and J.W. Posakony, unpubl.), are broadly or ubiquitously ex-

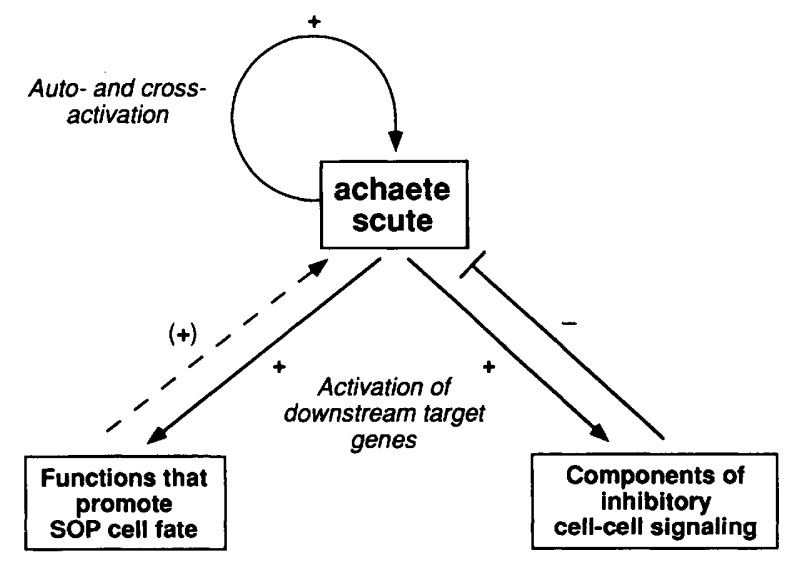

Figure 6. Summary of the regulatory activities of ac and sc in imaginal discs. pressed in third-instar larval imaginal discs, including the territories in which proneural clusters arise. Thus, these and other elements of the inhibitory signaling machinery are available to imaginal disc cells independently of their proneural potential. However, our results indicate that only in the proneural clusters - that is, only in those cells in which ac and sc are active as transcriptional activators-will the complete ensemble of gene functions required to stably determine a single SOP be expressed.

\section{Materials and methods}

\section{Drosophila stocks}

Flies were raised on standard yeast/cornmeal/molasses/agar medium. Transformant lines carrying promoter-reporter gene fusions [Brd 1.5-lacZ, Brd 1.5M-lacZ, Brd 0.19-lacZ, Brd $0.19 \mathrm{M}-1 \mathrm{lacZ}, E(\mathrm{spl}) \mathrm{m} 7$ 0.5-lacZ, and $E(\mathrm{spl}) \mathrm{m} 7 \mathrm{0.5M}-\mathrm{lacZ}$ ] were characterized as homozygous stocks, except where the chromosome carrying the transgene insertion was homozygous lethal. All other mutations and chromosomes are described in Lindsley and Zimm (1992).

\section{General molecular biology procedures}

Molecular biology techniques not described in detail below are described in Ausubel et al. (1987) and Sambrook et al. (1989).

\section{In situ hybridization}

In situ hybridization was performed on imaginal discs dissected from late third-instar larvae as described by Tautz and Pfeifle (1989), with modifications by Jiang et al. (1991) and Schweisguth and Posakony (1992). Digoxygenin-labeled antisense RNA probes for $s c, B r d, E(s p l) m 7, E(s p l) m 8, E(s p l) m 4$, sca, and lacZ were prepared as described by the manufacturer (Boehringer Mannheim).

\section{$\beta$-Galactosidase activity staining}

Imaginal discs dissected from late third-instar larvae were stained for $\beta$-galactosidase activity as described by Romani et al. (1989).

Isolation and sequencing of promoter fragments

Brd

A 1491-bp EcoRI-SalI Brd promoter fragment containing 42 bp of $5^{\prime}$-untranslated sequence was isolated from a Lambda FIX II (Stratagene) genomic DNA clone (M.W. Leviten and J.W. Posakony, in prep.), and subcloned into the $\mathrm{XbaI}$ site of pBluescript $\mathrm{KS}$ (+) (Stratagene) using XbaI linkers, to create pBSBrd-1.5.

$\mathrm{E}(\mathrm{spl}) \mathrm{m} 7$

A 543-bp XbaI-XmnI $E(s p l) m 7$ promoter fragment containing $65 \mathrm{bp}$ of 5 '-untranslated sequence was isolated from a $1.6-\mathrm{kb}$ genomic DNA clone (provided by D. Kosman, R. Park, and M. Levine, University of California, San Diegol and subcloned into the $X b a I$ site of pBluescript $\mathrm{KS}|+|$ using $X b a I$ linkers, to create pBSm7-0.5.

\section{E(spl) $\mid \mathrm{m} 4$}

A 450-bp DNA fragment containing the $E(s p l) m 4$-coding region 
was amplified by the polymerase chain reaction (PCR) from genomic DNA prepared from Canton $S$ flies using the following primers (Operon Technologies): M4A, 5'-CTCTGAATTCATGTGCCAGAACAAGATC-3'; and M4B 5'-CTCTGTCGACTTAGGCCTGAACCCAACG-3'. The PCR product was ligated into EcoRI/SalI-digested pBluescript $\mathrm{KS}|+|$ vector. This fragment was used as a probe for isolation of a genomic DNA clone containing the $E(s p 1) m 4$ gene from an EMBL3 library (kindly provided by R. Blackman, University of Illinois, Urbana). A 2.0$\mathrm{kb}$ XhoI-HinDIII fragment from the EMBL3 clone containing $503 \mathrm{bp}$ of promoter sequence was subcloned into pBluescript $\mathrm{KS} \mid+1$.

The nucleotide sequences of all fragments described above were obtained or verified by double-stranded DNA sequencing. Sequences of the 5 '-flanking regions of $B r d, E(s p l) m 7$, and $E$ (spl) $m 4$ have been deposited in the GenBank data base.

\section{Germ-line transformation}

The 1491-bp Brd and the 543-bp E(spl)m7 XbaI-linkered promoter fragments (see above) were cloned into the CaSpeRlacZ P-element transformation vector described in Margolis et al. (1994) and Van Doren et al. (1992) to create pBrd 1.5-lacZ and pm7 0.5-lacZ, respectively. pBrd 0.19-lacZ was created by digesting $\mathrm{pBrd} 1.5-\mathrm{lacZ}$ with PstI and self-ligating the vector-containing fragment. The mutant forms of these constructs, $\mathrm{pBrd}$ 1.5M-lacZ, pm7 0.5M-lacZ, and pBrd 0.19M-lacZ (see below), were created identically to their wild-type counterparts. Transgenic flies were generated by P-element-mediated germ-line transformation techniques (Rubin and Spradling 1982) using $w^{1118}$ as the recipient strain.

\section{Site-specific mutagenesis}

Site-specific mutagenesis was performed using pBSBrd-1.5, a mutant oligonucleotide, convenient restriction sites, and PCR to generate $\mathrm{pBSBrd}-1.5 \mathrm{M}$. The high-affinity $\mathrm{da} / \mathrm{ac}-\mathrm{sc}$ binding site Brd E1 (Fig. 2; Table 1) in this plasmid was changed from GCAGGTGT to GCCGGTTT and verified by DNA sequencing. pBrd $1.5 \mathrm{M}-\mathrm{lacZ}$ and $\mathrm{pBrd} 0.19 \mathrm{M}-\mathrm{lacZ}$ were then constructed as described above. pBSm7-0.5M was generated using a Transformer Site-Directed Mutagenesis Kit (Clontech). The two high-affinity da/ac-sc binding sites $\mathrm{m} 7 \mathrm{E} 2$ and $\mathrm{m} 7 \mathrm{E} 3$ (Fig. 2, Table 1) in pBSm7-0.5 were changed from GCAGGTGG to GCCGGTTG and from GCAGGTGT to GCCGGTTT, respectively. After sequence verification, pm7 $0.5 \mathrm{M}-\mathrm{lacZ}$ was constructed as described above.

\section{DNA-binding assays}

Plasmid constructs for bacterial expression of full-length ac, sc, and da proteins will be described elsewhere (P.A. Powell and J.W. Posakony, in prep.). GST fusion proteins were isolated from bacterial cultures that had been grown at $37^{\circ} \mathrm{C}$ to an $\mathrm{OD}_{600}$ of 0.2 , shifted to $30^{\circ} \mathrm{C}$ and grown to an $\mathrm{OD}_{600}$ of $0.6-0.7$, and induced with $400 \mu \mathrm{M}$ final IPTG at $30^{\circ} \mathrm{C}$ for $1 \mathrm{hr}$. The cells were washed in PBS and resuspended in lysis buffer $\left[25 \mathrm{mM} \mathrm{K}^{+} \mathrm{HEPES}\right.$ (pH 7.5), $0.3 \mathrm{M} \mathrm{KCl}, 12.5 \mathrm{~mm} \mathrm{MgCl}_{2}, 1 \mathrm{~mm}$ EDTA, 0.1\% NP-40, $10 \%$ glycerol, $1 \mathrm{~mm}$ DTT, $1 \mathrm{mM}$ PMSF, $2 \mu \mathrm{g} / \mathrm{ml}$ of aprotinin, 2 $\mu \mathrm{g} / \mathrm{ml}$ of leupeptin, and $1 \mu \mathrm{g} / \mathrm{ml}$ of pepstatin] to which lysozyme was added to $0.625 \mathrm{mg} / \mathrm{ml}$. Following a $15-\mathrm{min}$ incubation on ice, cells were sonicated (Fisher Dismembrator model 300 ) for $5 \times 30 \mathrm{sec}$ at $60 \%$ power at 30 -sec intervals. The supernatant from the lysate was mixed with glutathione-Sepharose beads (Pharmacia) and gently agitated for $30 \mathrm{~min}$ at $4^{\circ} \mathrm{C}$. The beads containing the fusion proteins were washed 4 times in lysis buffer without glycerol, and then 3 times in elution buffer lacking glutathione $\left[25 \mathrm{~mm} \mathrm{~K}{ }^{+}\right.$HEPES $(\mathrm{pH} 8.0), 1 \mathrm{~mm}$ DTT, 1 $\mathrm{mM}$ PMSF, $2 \mu \mathrm{g} / \mathrm{ml}$ of aprotinin, $2 \mu \mathrm{g} / \mathrm{ml}$ of leupeptin, and 1 $\mu \mathrm{g} / \mathrm{ml}$ of pepstatin]. Fusion proteins were eluted from the beads by incubation in elution buffer containing $10 \mathrm{~mm}$ glutathione. The beads were then pelleted and the supernatant was dialyzed [25 mM K ${ }^{+}$HEPES (pH 7.5), $50 \mathrm{mM} \mathrm{KCl,} 5 \mathrm{~mm} \mathrm{MgCl}_{2}, 0.1 \mathrm{~mm}$ EDTA, and $1 \mathrm{~mm} \mathrm{DTT]} 3 \times 4$ liters, overnight at $4^{\circ} \mathrm{C}$. Eluted proteins were frozen in aliquots in $10 \%$ glycerol. Doublestranded DNA oligonucleotide probes and specific competitor oligonucleotides were synthesized by Operon Technologies. Each probe or competitor corresponds to the sequence surrounding a single wild-type or mutant E-box site (bold letters) found in the proximal promoters of $B r d, E(s p l) m 7, E(s p l) m 8$, or sca (see Fig. 2). The sequences are as follows:

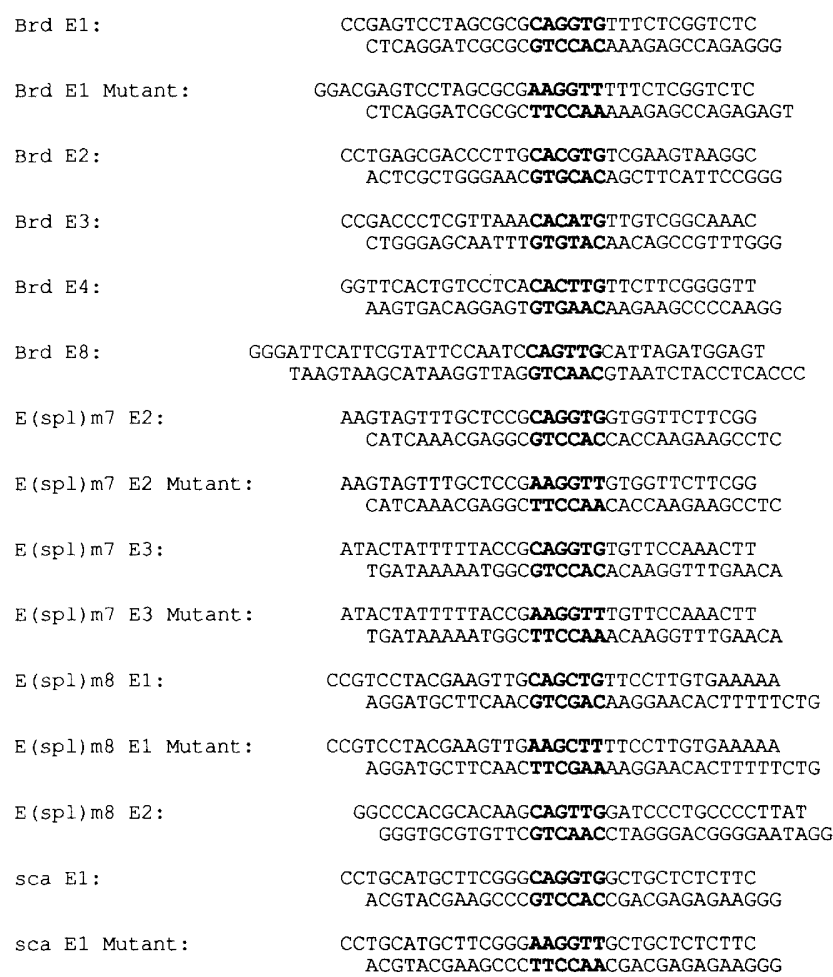

For electrophoretic mobility shift assays, oligonucleotide probes were end-labeled and annealed as described in Van Doren et al. (1991). Bacterial fusion proteins $(0-400 \mathrm{ng})$ were mixed in a final volume of $6 \mu \mathrm{l}$ of dialysis buffer plus $10 \%$ glycerol and incubated for $20 \mathrm{~min}$ at $25^{\circ} \mathrm{C}$. After incubation, the following were added: $1 \mu \mathrm{l}$ of probe $\left(0.025 \mu \mathrm{M}\right.$ at $\left.1-8 \times 10^{5} \mathrm{cpm} / \mu \mathrm{l}\right)$ in TE buffer, $1 \mu \mathrm{l}$ of $1 \mathrm{mg} / \mathrm{ml}$ poly[d(I,C)] or poly[d(A,T)] (Sigma), $1 \mu$ l of $4 \times$ dialysis buffer (or for competition experiments, $1 \mu l$ of 2.5 $\mu \mathrm{M}$ (100×; Fig. 3D, last nine lanes) or $5 \mu \mathrm{M}$ (200×; Fig. 3D, first eight lanes) unlabeled competitor oligonucleotide in $4 \times$ dialysis buffer], and $1 \mu \mathrm{l}$ of $0.275 \mathrm{mg} / \mathrm{ml}$ denatured salmon sperm DNA. Presumably because of the high GC content of da/ac-sc binding sites, $\operatorname{poly}[\mathrm{d}(\mathrm{A}, \mathrm{T})]$ was found to be a better nonspecific competitor than poly[d(I,C)], so the former was used in the low-affinity binding site competition experiment (Fig. 3D, first eight lanes). The mixture was incubated for $40 \mathrm{~min}$ at $25^{\circ} \mathrm{C}$. The reactions were electrophoresed on prerun $0.5 \times \mathrm{TBE} / 4 \%$ acrylamide gels $(2$ $\mathrm{mm}$ thick $\times 15 \mathrm{~cm}$ long/ for $3 \mathrm{hr}$ at $125 \mathrm{~V}$. Gels were 
fixed in $25 \%$ methanol $/ 7 \%$ acetic acid for $30 \mathrm{~min}$ and dried prior to autoradiography on X-Omat AR film (Kodak) at $-80^{\circ} \mathrm{C}$ with an intensifying screen.

\section{Acknowledgments}

We are grateful to Trish Powell for proneural protein expression constructs and for purified proteins, Dave Nellesen for cloning assistance, Dave Kosman and Ron Park for E(spl) genomic DNA clones, Nick Brown for cDNA libraries, and Ron Blackman for an EMBL3 genomic DNA library. We thank Adina Bailey, Josh Kavaler, Mike Levine, Kees Murre, Trish Powell, and Mark Van Doren for critical comments and suggestions on the manuscript. This work was supported by a National Science Foundation predoctoral fellowship and a San Diego Research Fellowship (A. S.), and by National Institutes of Health grant GM46993 to J.W.P.

The publication costs of this article were defrayed in part by payment of page charges. This article must therefore be herreby marked "advertisement" in accordance with 18 USC section 1734 solely to indicate this fact.

\section{Note added in proof}

The GenBank accession numbers for the promoter sequences described in this paper are U13067 (Brd); U13068 (E(Spl)m4); and $\mathrm{U} 13069(E(s p 1) \mathrm{m} 7)$.

\section{References}

Ausubel, F.M., R. Brent, R.E. Kingston, D.D. Moore, J.G. Seidman, J.A. Smith, and K. Struhl. 1987. Current protocols in molecular biology. Wiley Green, New York.

Baker, N.F., M. Mlodzik, and G.M. Rubin. 1990. Spacing differentiation in the developing Drosophila eye: A fibrinogenrelated lateral inhibitor encoded by scabrous. Science 250: 1370-1377.

Bang, A. and J.W. Posakony. 1992. The Drosophila gene Hairless encodes a novel basic protein that controls alternative cell fates in adult sensory organ development. Genes \& Dev. 6: 1752-1769.

Cabrera, C.V. and M.C. Alonso. 1991. Transcriptional activation by heterodimers of the achaete-scute and daughterless gene products of Drosophila. EMBO J. 10: 2965-2973.

Cagan, R.L. and D.F. Ready. 1989. Notch is required for successive cell decisions in the developing Drosophila retina. Genes \& Dev. 3: 1099-1112.

Cronmiller, C. and C. Cummings. 1993. The daughterless gene product in Drosophila is a nuclear protein that is broadly expressed throughout the organism during development. Mech. Dev. 42: 159-169.

Cubas, P., J.-F. de Celis, S. Campuzano, and J. Modolell. 1991. Proneural clusters of achaete-scute expression and the generation of sensory organs in the Drosophila imaginal wing disc. Genes \& Dev. 5: 996-1008.

Delidakis, C. and S. Artavanis-Tsakonas. 1992. The Enhancer of split [ $($ (spl)] locus of Drosophila encodes seven independent helix-loop-helix proteins. Proc. Natl. Acad. Sci. 89: 87318735.

Delidakis, C., A. Preiss, D.A. Hartley, and S. Artavanis-Tsakonas. 1991. Two genetically and molecularly distinct functions involved in early neurogenesis reside within the Enhancer of split locus of Drosophila melanogaster. Genetics 129: 803-823.

Fehon, R.G., P.J. Kooh, I. Rebay, C.L. Regan, T. Xu, M.A.
Muskavitch, and S. Artavanis-Tsakonas. 1990. Molecular interactions between the protein products of the neurogenic loci Notch and Delta, two EGF-homologous genes in Drosophila. Cell 61: 523-534.

Fehon, R.G., K. Johansen, I. Rebay, and S. Artavanis-Tsakonas. 1991. Complex cellular and subcellular regulation of Notch expression during embryonic and imaginal development of Drosophila: Implications for Notch function. $J$. Cell Biol. 113: 657-669.

Fortini, M. and S. Artavanis-Tsakonas. 1993. Notch: Neurogenesis is only part of the picture. Cell 75: 1245-1247.

Furukawa, T., M. Kawaichi, N. Matsunami, H. Ryo, Y. Nishida, and T. Honjo. 1991. The Drosophila RBP-Jk gene encodes the binding protein for the immunoglobulin JK recombination signal sequence. I. Biol. Chem. 266: 23334-23340.

Furukawa, T., S. Maruyama, M. Kawaichi, and T. Honjo. 1992. The Drosophila homolog of the immunoglobulin recombination signal-binding protein regulates peripheral nervous system development. Cell 69: 1191-1197.

Gonzalez-Crespo, S. and M. Levine. 1993. Interactions between dorsal and helix-loop-helix proteins initiate the differentiation of the embryonic mesoderm and neuroectoderm in Drosophila. Genes \& Dev. 7: 1703-1713.

Hartenstein, V. and J.W. Posakony. 1989. Development of adult sensilla on the wing and notum of Drosophila melanogaster. Development 107: 389-405.

Heitzler, P. and P. Simpson. 1991. The choice of cell fate in the epidermis of Drosophila. Cell 64: 1083-1092.

. 1993. Altered epidermal growth factor-like sequences provide evidence for a role of Notch as a receptor in cell fate decisions. Development 117: 1113-1123.

Hinz, U., B. Giebel, and J.A. Campos-Ortega. 1994. The basichelix-loop-helix domain of Drosophila lethal of scute protein is sufficient for proneural function and activates neurogenic genes. Cell 76: 77-87.

Jarman, A.P., Y. Grau, L.Y. Jan, and Y.N. Jan. 1993. atonal is a proneural gene that directs chordotonal organ formation in the Drosophila peripheral nervous system. Cell 73: 1307-1321.

Jarman, A., E. Grell, L. Ackerman, L. Jan, and Y. Jan. 1994. atonal is the proneural gene for Drosophila photoreceptors. Nature 369: 398-400.

Jiang, J. and M. Levine. 1993. Binding affinities and cooperative interactions with bHLH activators delimit threshold responses to the dorsal gradient morphogen. Cell 72: 741-752.

Jiang, J., D. Kosman, Y.T. Ip, and M. Levine. 1991. The dorsal morphogen gradient regulates the mesoderm determinant twist in early Drosophila embryos. Genes \& Dev. 5: 18811891.

Klämbt, C., E. Knust, K. Tietze, and J. Campos-Ortega. 1989. Closely related transcripts encoded by the neurogenic gene complex Enhancer of split of Drosophila melanogaster. EMBO I. 8: 203-210.

Knust, E., K.A. Bremer, H. Vässin, A. Ziemer, U. Tepass, and J.A. Campos-Ortega. 1987a. The Enhancer of split locus and neurogenesis in Drosophila melanogaster. Dev. Biol. 122: 262-273.

Knust, E., K. Tietze, and J.A. Campos-Ortega. 1987b. Molecular analysis of the neurogenic locus Enhancer of split of Drosophila melanogaster. EMBO J. 6: 4113-4123.

Knust, E., H. Schrons, F. Grawe, and J.A. Campos-Ortega. 1992. Seven genes of the Enhancer of split complex of Drosophila melanogaster encode helix-loop-helix proteins. Genetics 132: $505-518$.

Kooh, P.J., R.G. Fehon, and M.A. Muskavitch. 1993. Implications of dynamic patterns of Delta and Notch expression for cellular interactions during Drosophila development. Devel- 
opment 117: 493-507.

Kramatschek, B. and J.A. Campos-Ortega. 1994. Neuroectodermal transcription of the Drosophila neurogenic genes E(spl) and $H L H-m 5$ is regulated by proneural genes. Development 120: 815-826.

Lindsley, D.L. and G.G. Zimm. 1992. The genome of Drosophila melanogaster. Academic Press, San Diego, CA.

Margolis, J., M. Borowsky, C. Shim, and J. Posakony. 1994. A small region surrounding the distal promoter of the hunchback gene directs maternal expression. Dev. Biol. 163: 381388.

Martinez, C. and J. Modolell. 1991. Cross-regulatory interactions between the proneural achaete and scute genes of Drosophila. Science 251: 1485-1487.

Martinez, C., J. Modolell, and J. Garrell. 1993. Regulation of the proneural gene achaete by helix-loop-helix proteins. Mol. Cell. Biol. 13: 3514-3521.

Mlodzik, M., N.E. Baker, and G.M. Rubin. 1990. Isolation and expression of scabrous, a gene regulating neurogenesis in Drosophila. Genes \& Dev. 4: 1848-1861.

Parody, T. and M. Muskavitch. 1993. The pleiotropic function of Delta during postembryonic development of Drosophila melanogaster. Genetics 135: 527-539.

Posakony, J.W. 1994. Nature versus nurture: Asymmetric cell divisions in Drosophila bristle development. Cell 76: 415418.

Romani, S., S. Campuzano, E.R. Macagno, and J. Modolell. 1989. Expression of achaete and scute genes in Drosophila imaginal discs and their function in sensory organ development. Genes \& Dev. 3: 997-1007.

Rubin, G.M. and A.C. Spradling. 1982. Genetic transformation of Drosophila with transposable element vectors. Science 218: 348-353.

Ruel, L., M. Bourouis, P. Heitzler, V. Pantesco, and P. Simpson. 1993. Drosophila shaggy kinase and rat glycogen synthase kinase- 3 have conserved activities and act downstream of Notch. Nature 362: 557-560.

Sambrook, J., E.F. Fritsch, and T. Maniatis. 1989. Molecular cloning: A laboratory manual. Cold Spring Harbor Laboratory Press, Cold Spring Harbor, New York.

Schrons, H., E. Knust, and J.A. Campos-Ortega. 1992. The Enhancer of split complex and adjacent genes in the $96 \mathrm{~F}$ region of Drosophila melanogaster are required for segregation of neural and epidermal progenitor cells. Genetics 132: 481503.

Schweisguth, F. and J.W. Posakony. 1992. Suppressor of Hairless, the Drosophila homolog of the mouse recombination signal-binding protein gene, controls sensory organ cell fates. Cell 69: 1199-1212.

Skeath, J.B. and S.B. Carroll. 1991. Regulation of achaete-scute gene expression and sensory organ pattern formation in the Drosophila wing. Genes \& Dev. 5: 984-995.

Tautz, D. and C. Pfeifle. 1989. A non-radioactive in situ hybridization method for the localization of specific RNAs in Drosophila embryos reveals translational control of the segmentation gene hunchback. Chromosoma 98: 81-85.

Tietze, K., N. Oellers, and E. Knust. 1992. Enhancer of split ${ }^{D}$, a dominant mutation of Drosophila, and its use in the study of functional domains of a helix-loop-helix protein. Proc. Natl. Acad. Sci. 89: 6152-6156.

Tun, T., Y. Hamaguchi, N. Matsunami, T. Furukawa, T. Honjo, and M. Kawaichi. 1994. Recognition sequence of a highly conserved DNA binding protein RBP-Jк. Nucleic Acids Res. 22: 965-971.

Van Doren, M., H.M. Ellis, and J.W. Posakony. 1991. The Drosophila extramacrochaetae protein antagonizes sequence-spe- cific DNA binding by daughterless/achaete-scute protein complexes. Development 113: 245-255.

Van Doren, M., P.A. Powell, D. Pasternak, A. Singson, and J.W. Posakony. 1992. Spatial regulation of proneural gene activity: Auto- and cross-activation of achaete is antagonized by extramacrochaetae. Genes \& Dev. 6: 2592-2605. 


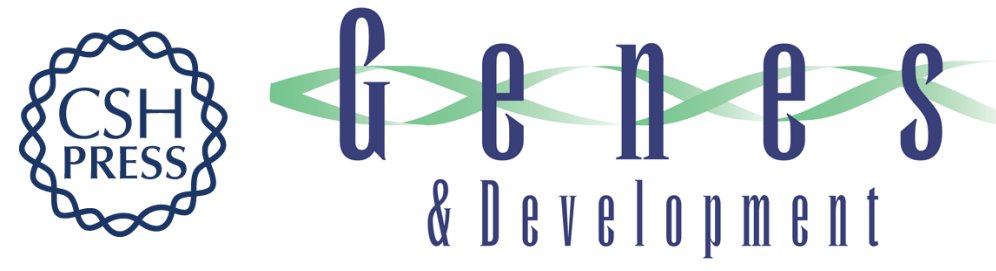

\section{Direct downstream targets of proneural activators in the imaginal disc include genes involved in lateral inhibitory signaling.}

A Singson, M W Leviten, A G Bang, et al.

Genes Dev. 1994, 8:

Access the most recent version at doi:10.1101/gad.8.17.2058

References This article cites 45 articles, 26 of which can be accessed free at:

http://genesdev.cshlp.org/content/8/17/2058.full.html\#ref-list-1

License

Email Alerting

Service

Receive free email alerts when new articles cite this article - sign up in the box at the top right corner of the article or click here.

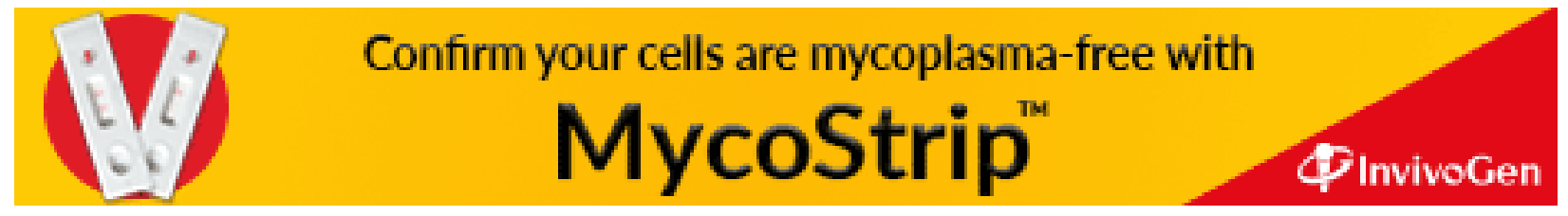

